\section{The Open Book Of The Humanities}

\section{Ignaz Cassar}

James J. Bono, Tim Dean, Ewa Plonowska Ziarek (eds), A Time for the

Humanities: Futurity and the Limits of Autonomy, Fordham University Press, New York 2008; pp273, £21.95 paperback.

What does the future hold for the humanities? Might there be a future that remains receptive to the intellectual practices of the humanities? Indeed, might there be a future at all that will still matter to those who identify themselves as humanists? The collection of essays brought together in A Time for the Humanities prompts us to recognize that the question of the uncertain futures for the humanities is first of all a critical matter for the humanities themselves. As such, the question about the fate of the humanities and their critical legacies in the light of economic uncertainty, political scepticism, and their potential redundancy as a field and scholarly practice is a pressing one. ${ }^{1}$ Yet this is not just a question of ensuring that the right kind of future is secured, one within which the humanities are guaranteed the presence they might claim to deserve. And neither is it a matter for simply arguing for the irreplaceability of the humanities by producing the evidential goods for their purportedly indispensable role within a society's knowledge economies. ${ }^{2}$ It is rather a question of the field's autonomy versus its heteronomy - and it is this question that is opened out in A Time for the Humanities.

At a time when the humanities are undergoing substantial changes it might be hard not to empathize with the hopeful humanist who wishes to stay abreast so as to adapt to unpredictable times to come. In other words, if the humanities are deemed to lose the outlines they were once entrusted with, and thus also their alleged autonomy within which the humanist could take shelter, then one might say that it is not unreasonable to invest in the future. (Is not 'investing in the future' at once capitalism's unrelenting premise and its consolation?) Still, the returns of this investment will be more than one could reason with. What the humanities may yield from the endowments of futurity derives its force also from the nonhuman agency of time, thus bringing to the fore 'the constitutive tension between human and nonhuman aspects of agency and praxis' (p3). Or put differently, 'the orientation of any praxis towards the unforeseeable future' involves manifestations 'of the nonhuman "agency" of time' (p3).

The standpoints adopted in A Time for the Humanities, particularly those emphasizing non-human agency, direct us towards a thinking as to how acts of practice in the humanities cannot be solely reduced to the building of an autonomous subject, but how the very potentiality sustaining such practice is 'based on the heteronomy rather than the autonomy of the subject' (p4). As the editors propose: 'Unlike related terms in contemporary theory - such
1. The editors attend to discussions that address, within the US context, the transformations of the postwar university with regards to issues such as research ethics, internationalization, academic governance and public accountability. See Jonathan R.

Cole, Elinor G. Barber, Stephen R. Graubard (eds), The Research University in a Time of Discontent, Baltimore, The Johns Hopkins University Press, 1994; David A. Hollinger (ed), The Humanities and the Dynamics of Inclusion since World War II, Baltimore, The Johns Hopkins University 2006; David Marshall (ed), 'The Humanities and its Publics', ACLS Occasional Paper 61, 2006, www. acls.org/Publications/ OP/61_Humanities_ and_Püblics.pdf.

2. Those engaging in academic research in the United Kingdom will be reminded of the political attention given to 'impact' since 2008 as a key parameter to assess the quality of institutional research in UK higher education through the so-called 'Research Excellence Framework' and its call for ensuring that academic outcomes be socially and economically contributory. The gap of contention opens then when the 'contributory', defined as 'positive impact', does not, or, perhaps, cannot meet the positivistic 
intent it is attributed by a given politics. For a range of policy documents in relation to 'impact', see http://www.hefce. ac.uk/research/ref/

as heterogeneity, otherness, or difference - the notion of heteronomy, in addition to maintaining the reference to differentiation and to the multiplicity of heterogeneous principles, more specifically links "otherness" to the questioning of subjective autonomy and agency as the principle of freedom' (p4). What follows, then, is that in order to realize the critical drives of the future, that is, to expose the humanities to futurity's 'ought to', entails the unveiling of the agency of time itself. What is more, such turning towards the future brings to the fore the broader entanglements of human praxis of doing and thinking with the non-human - of time, its demands and stakes, but also of the letter and its inscribing forces, of the topos of the unconscious and its drives, of the technology of writing and its apparatuses, of the humanities' edict and its evolving disciplinary accounting.

Such premises as the technology of writing and its apparatuses are echoed in the book's topical structuring, which gathers the viewpoints of the twelve contributors around four thematic parts: 'The New and its Risks' (Paola Marrati, Andrew Benjamin, Martin Jay); 'Rhetoric and the Future of the Political' (Ernesto Laclau, Jean-Luc Nancy, Rey Chow); 'Heteronomy and Futurity in Psychoanalysis' (Rudi Visker, Tim Dean, Elizabeth Weed); 'Inventions' (Steve McCaffery, N. Katherine Hayles, Doris Sommer). And while in some of the contributions the authors impart longstanding research interests with accomplished scholarly devotion, these essays attain, nonetheless, a significant momentum from drawing compelling critical synergies across each other in support of the book's editorial objectives. As such, this is an edited collection that displays confidence with what it is, without requiring the editorial overdetermination that favours artificial hyperbole, or the kind of editorial restraint that casts little more than a shadow of monotonous guidance onto its texts. Providing an open but deeply engaging arena for thinking the futures of the humanities, A Time for the Humanities brings into view, from a range of theoretical approaches, how the 'makings' of such futures simultaneously spring forth, in fact, from ' $[\mathrm{t}] \mathrm{he}$ multiple senses of human and nonhuman agency [...]' (p4).

Remaining in conversation with thinkers indebted to the traditions of continental philosophy and psychoanalysis and their critical conjugations within queer, feminist and postcolonial thought, the collected positions are an encouraging demonstration of the spirit of interdisciplinarity. In this light, the editors' insistence 'on the necessity of thinking together all three "inhuman" dimensions of human practice: digital technology, utopian temporality, and “extimate" sexuality' (p4) is also convincingly put into practice in the book. The chapters address these problematics from different contexts of creation, including filmmaking, art practice, writing, architecture, rhetoric, critique and philosophical practice, without detracting this reader from gaining a strong sense of their inter-related critical purpose. Always brought into relief in their intersections with the wider socio-historical and political conditions which frame these practices, the texts ultimately aim at revealing heteronomy ' $[\ldots]$ as an enabling rather than threatening condition of agency' so as to permit 'a 
shift from recuparable difference [...] to unimaginable, not-yet-encountered potentialities' (p5).

The revelation of heteronomy as an enabling condition brings into view another significant issue - regardless of one's willingness for adaptation or reluctance thereof - namely the relational dynamics between an unknown outside that is perceived as being potentially antagonistic to the humanities and their implicit missions, and, conversely, in wishing to assert their own future, the humanities' internally imposed obligation to react to that outside. It is this problematization that provides the wider conceptual frame through which the contributions assembled in A Time for the Humanities invite the reader to weigh up to what extent the humanities will continue carrying their weight. So, how should the humanist react then in this moment of heightened self-doubt? What kinds of actions are to be taken? And just what future ought there to be enacted?

It is those who can adapt, we have learnt, that become the survivors. So surely the humanists' instincts would follow suit in order to warrant a future in which the humanists have not become another extinct species. If the humanities want to survive, then adaptation is the necessary means to an end for building a future in which they still feature. And it is precisely on this point that the book's critical voices intervene. We might dare to predict - and, at times, might well be able to do so more or less accurately, too - what the future holds, but such casting forth relies on the pre-diction of what is to become the 'future'. What is cast aside thereby is the need to take into consideration the dimensions of futurity. As the editors call to mind in their introduction to the volume, 'the urgent concern with the future cannot be limited to critical assessments of our situation or to practical projects for change' (p2). To think of the future, to predict its shape and one's place within it, also brings about an opening up of one's self to future's temporal condition: futurity. Hence, if we want the humanities to critically account for their future, indeed, if the future is to be a critical matter at all, then we also have to take into account that which remains outside the accountable - which is exactly what can become revealed when allowing for the futurity of future. 'This necessary implication', the editors write, 'arises precisely because the very force of the "ought to" - on which the specific content of pragmatic prescriptions depends - opens the unknown and unforeseeable dimensions of temporality' (p3).

'Although always embedded in the historical situation, the relation to the future, whether theoretical or prescriptive, is counterfactual; it exceeds the present possibilities of thought and action' (p3). This, the book's contributors caution accordingly, should not be taken as an excuse to drift off into an escapism of the wistful kind in the hope of exempting the humanities from that which is supposedly not meant to fall into their field of reference; or worse, read the potentialities induced by embracing the (non-)signifying dimensions of futurity as a pretext for divesting the humanities of all things either 'non-humanistic' or, indeed, 'nonhuman' - a sort of decontamination of the field as if thereby to exonerate the humanities from their professed

3. A detour into French is useful to differentiate more clearly the semantic layers of 'futurity' and 'future', as French uses 'l'avenir' and 'le futur' to denote futural dimensions. Futurity tends to correspond with the French 'l'avenir', that which is to come, which arrives and breaks through, in contradistinction to 'le futur', which lies in anticipation and is predicted, in the sense of a present future. For an incisively rendered account of 'futurity' and 'future' in French deconstruction, see Jean-Paul Martinon, On Futurity: Malabou, Nancy and Derrida, Houndmills, Palgrave Macmillan, 2007. 
4. On Humboldt's conception of the subject-enabling Bildung, see David Sorkin, 'Wilhelm Von Humboldt: The Theory and Practice of Self-Formation (Bildung), 17911810', Journal of the History of Ideas, 44: 1 , 1983: 55-73.

5. I borrow the term " to-come" from Martinon who, in drawing on Derrida's work on futurity, employs it in English to render the connotations associated with the work of the French 'l'avenir' performed in 'à-venir': “Тocome" is at once yet-to-come [avenir] in the way it relates to some future present (action), and coming [avenant] in the sense of a secret "unhingement" that comes to disturb this future present, this avenir, action, or event' (p3). À-venir or spacing (and) temporizing is therefore related to a certain alterity, but one which defies anticipation, reappropriation, calculation, or any form of predetermination' (p5). Jean-Paul Martinon, $O n$ Futurity, pp1-26. dilemmas about a compromised identity and the anxieties such might stir up. The historic challenges instigated by information technology and digitality, prosthetically refiguring and expanding bodies, postcolonial unframings of geopolitical adherence, arousing assertions of sexological non-normativity, etc., have not only left clear marks on the disciplinary corpus of the humanities but have also changed its customs of practice and the means employed. At this point, one may think, with contributor N. Katherine Hayles, of that most symbolic device with which the humanist's work is so intimately associated, the book, and how its form is being taken to bits by the makings of digitality and its informational structures. And it is in looking towards the future that some cannot but foresee the book becoming a relic of the past. Dead ends.

The vision of an impending 'death of the book' shall serve here as just one example for the recurring and perhaps, symptomatic, anxieties of terminality underlying the fields of the humanities. A Time for the Humanities takes issue with these anxieties and reflects on the motives for their returns; in the convergence of these anxieties the phantom image of a time without the humanities comes into manifestation. Indeed, what is at stake, in taking once more the book as representative cipher for the current concerns encroaching the humanities' identity, is the recognisability of the corpus of the humanities and its independence from other fields. Thus, the 'demise' of the book is significant not so much because a treasured object might reach its use-by date, but rather because of history's connotative inscriptions of the book as the very guarantor of humanistic virtues - its pages symbolizing the enlightened values with which the humanities have come to identify: speculative thought, authorial freedom, creative play and the practices of self-formation that one associates with legacies such as Humboldt's vision of Bildung. ${ }^{4}$ Hence, the book's wearing away, imagined or actual, indicates also an unravelling of the assumed scope of the humanities and the disciplinary selfhood that furnishes the humanist with a space of her own.

A Time for the Humanities invites us to take up the task to keep the future engaged in the humanities: if our yearning to seize the future is not to run the risk of foreclosing us from the alterity of the not-yet-encountered, emerging from the spacing and temporizing work performed in the 'to-come' of futurity, ${ }^{5}$ then the question 'what does the future hold?' remains insufficient. The future, and the future of the humanities, is never just out 'there', or ahead of us; rather, it is inflecting the present, erupting within it. We may reach out for it, in anticipation, but the future already occupies us - now. 